\title{
Mobile-health technology: Can it Strengthen and improve public health systems of other developing countries as per Indian strategies? A systematic review of the literature
}

Introduction: The use of mobile-health ( $\mathrm{m}$-health) technology in public health is rapidly growing in developing countries. Objective: The objective of this study was to critically analyze the role and incorporation of $m$-health into public health systems of developing countries. Materials and Methods: A systematic review of related studies in the literature published in the last 10 years on key search word " $m$-health role in developing countries" was conducted using abstracting databases such as PubMed, World Health Organization, Cochrane, Google scholar and Bio-med Central. m-health studies on impact, effectiveness and evaluation of $\mathrm{m}$-health in public health were the three main criteria's taken for inclusion and studies on m-health in developed world as well data from thesis/dissertation were excluded in this review. This study is unique in methodology as similar kind of studies with this type of method and focus has not been carried out previously in the literature. Results and Discussion: From 23 articles, which finally met the inclusion criteria it was found that, a variety of $\mathrm{m}$-health applications and $\mathrm{m}$-health strategies are available in the mobile phone market of developing countries; however, lack of appropriate governmental regulation and oversight from health-care authorities are impacting the results in terms of costs, benefits and utility of these applications. Conclusions: m-health technology has the potential to impact greater health-care access to larger segments of rural populations and an improved capacity to meet the demand in developing countries as seen from Indian strategies, provided it is also intelligently used for improving health-care of people in developing countries.

Sanjeev Davey, Anuradha Davey ${ }^{1}$

Departments of Community Medicine, Muzaffarnagar Medical College \& Hospital, Muzaffarnagar, ${ }^{1}$ Subharti Medical College, Meerut, Uttar Pradesh, India

Address for the Correspondence: Dr. Sanjeev Davey, B-197, $3^{\text {rd }}$ Floor, Prashant Vihar, Sector-14 Rohini,

New Delhi - 110 085, India. E-mail: sanjeev_kumar175@ rediffmail.com

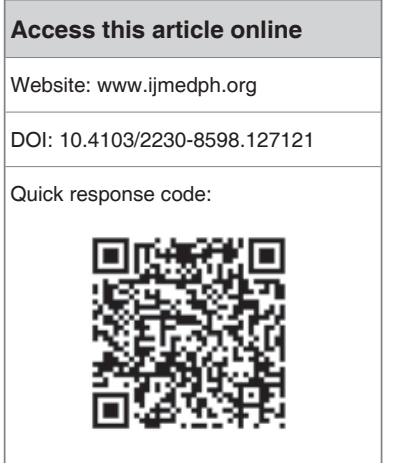

Key words: Developing countries, health system, health technology, health technology regulation, mobile health, technology regulation, telemedicine

\section{INTRODUCTION}

Mobile revolution has caused the use of mobile phones to spread rapidly in developing countries. In developing countries such as India and there can be around 15.56 crores of smart phone users by the end of 2017 and mobile-health (m-health) market opportunity is expected to reach 10\% of the total Asia-Pacific by 2020, which can explain that, how much potential this field has in the future for improvement of health services. ${ }^{[1]} \mathrm{m}$-health is supported by various kinds of mobile devices, such as mobile phones, patient monitoring devices, personal data assistant (a mobile device that functions as a personal information manager) and other wireless devices for providing patient health services and patient health information. ${ }^{[2]}$ For example, Information and communication technology (ICT), with the help of computers, mobile phones, communication satellites, patient monitors, are being used for health-care services and public health patient care information. ${ }^{[3]}$ Mobile communication technologies have enormous potential to reduce professional isolation-especially in rural areas and to provide ongoing support to health-care workers as well as patients. The key areas in which early and rapid gains can be achieved via m-health are: (a) maternal and child health (b) routine immunization, (c) integrated management of childhood illness, (d) disease surveillance and control especially for diseases of poverty such as human immunodeficiency virus (HIV) and acquired immunodeficiency syndrome (AIDS), malaria and tuberculosis (TB)- where significant 
resources have been mobilized to reduce the disease burden in low and middle income countries such as India. ${ }^{[4]} \mathrm{m}$-health can also improve the well-being of people in developing counties by various strategies, as mobile applications can:

1. lower costs

2. Improve the quality of health-care

3. Strengthen prevention,

4. Better emergency response systems (for road traffic accidents, emergency obstetric care)

5. Human resources coordination, management and supervision

6. Mobile synchronous (voice) and asynchronous short message service (SMS) telemedicine diagnostic and decision support to clinicians in remote areas,

7. Clinician-focused, evidence-based formulary, database and decision support information available at point-of-care,

8. Pharmaceutical supply chain integrity and patient safety systems

All these key areas can improve health outcomes in the longterm. Mobile technology has spread its roots rapidly into low-and middle-income nations. In India, a lot has been done in the field of $\mathrm{m}$-health applications with the launch of mobile services and with the majority of initiatives focused on spreading prevention and awareness messages across the spectrum.

\section{Emerging issues in m-health}

$\mathrm{m}$-health is not a subset or mobilization of e-health. m-health uses mobile phones to access data for key diseases such as HIV/AIDS. As a result the health system would require a means for managing, storing and assessing the data. Hence, e-health projects may operate as the backbone of $\mathrm{m}$-health projects. Increasing threats of communicable as well as non-communicable disease epidemics coupled with the shortage of health-care professionals is a challenge to achieving the health related millennium development goals (MDGs) in developing countries. The explosive growth of mobile communications may offer a new opportunity to promote quality health-care for people in developing countries. With the reach of mobile phones in developing countries than any other ICT and health infrastructures, ${ }^{[5]}$ Mobile phones are a very promising tool for disease control interventions in developing country like India, where its use of bulk-SMS (push and voice) messaging for diseases such as HIV/AIDS have found to be well accepted by the population. ${ }^{[6]}$ This systematic review therefore, seeks to understand the possible role and penetration capacity of $\mathrm{m}$-health in the health systems of other developing countries on the lines of Indian strategies.

\section{Objective of paper}

To systematically review and critically appraise the literature in the field on the role of $\mathrm{m}$-health in public health systems of developing countries and to understand ways, improvements may be supported by such system.

\section{MATERIALS AND METHODS}

A systematic review of studies on $m$-health in the literature on key search word " $\mathrm{m}$-health role in developing countries" published in the past 10 years was completed. This comprehensive systematic review was accomplished using abstracting databases such as PubMed, World Health Organization, Cochrane-database, Google-scholar and BioMed Central. $m$-health studies in developing countries focused on the impact, effectiveness and evaluation of $\mathrm{m}$-health in public health were the three main criteria's taken for inclusion in this systematic review, out of 46 studies selected at different points in the review process, 23 studies were excluded from developed world and thesis/ dissertation data was discarded. Only 23 studies related to developing countries with $\mathrm{m}$-health examples, finally met the desired criteria to draw conclusions. This study is very unique in methodology as similar kind of studies with this type of method and focus has not been carried out previously in the literature. Studies selection process and criteria is shown in the flow diagram given below.

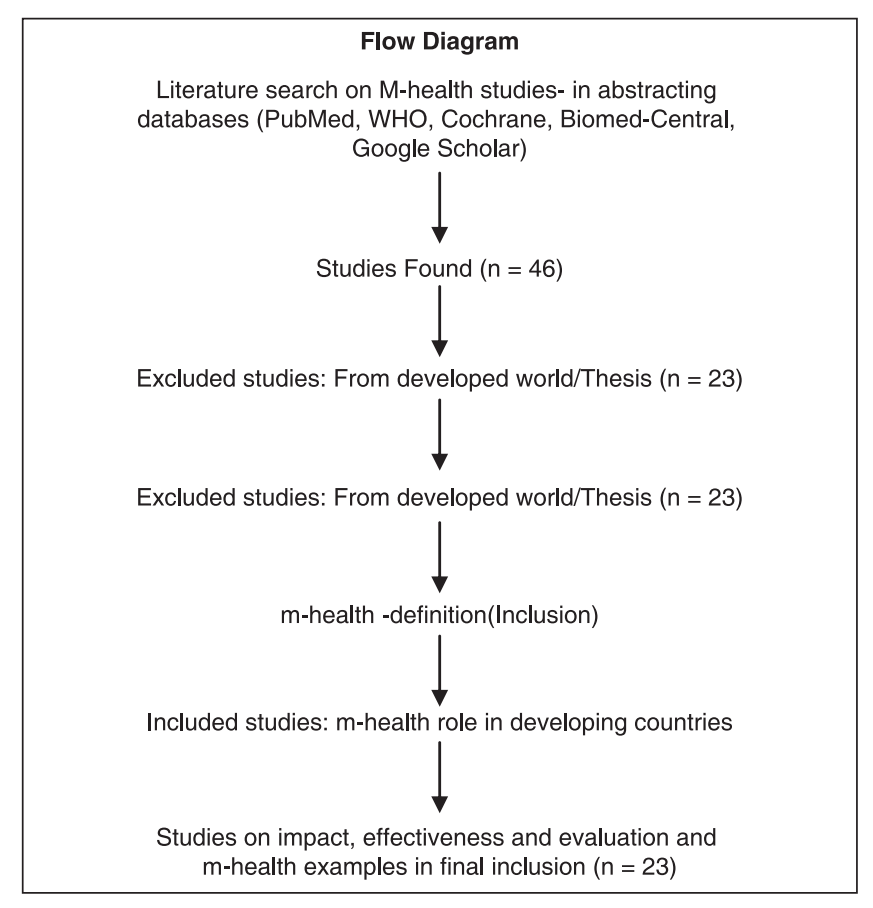

\section{RESULTS}

The results of this systematic review is summarized in Table 1 given below to find the key themes and concepts emerging from this systematic review of the literature.

\section{DISCUSSION}

$\mathrm{m}$-health working technologies as found in many studies can be explored in developing countries are as given below, in $\mathrm{m}$-health area, beyond mobile phones such as:

1. Wireless-enabled laptops and

2. Specialized health-related software applications: are currently developed, tested and marketed for use in the m-health field and many available technologies in low-and middle-income nations, are developing primarily in high-income countries.

3. Free and open source software, applications are making penetration in low-and middle-income countries. 
Many m-health technologies, which can be replicated in developing countries is shown in Table 2 given below as available from web. ${ }^{[7]}$

Let us see how m-health can further improve public health system of developing countries by its applicability and objectives as given below:

\section{M-health applications to public health using mobile devices $^{[5-7]}$}

1. Collecting community and clinical health data (Remotedata-collection) and delivery of healthcare information to practitioners, researchers and patients (Communication and training for health-care workers) ${ }^{[5-7]}$

2. Real-time monitoring of patient vital signs (Remotemonitoring $)^{[5-7]}$

3. Direct provision of care (Mobile-telemedicine) ${ }^{[5-7]}$

4. Diagnostic and treatment support (Remote - patientmanagement $)^{[5,6]}$

5. Diseases and epidemic outbreak tracking (Public-healthsurveillance $)^{[5,6]}$

6. Patients education and awareness (Information Education Communication and Behavior Change Communication (BCC) messages) $)^{[5,6]}$

7. Disaster warning (Disaster management) ${ }^{[5,6]}$

8. Communicable Diseases Management such as TB care with speed and the benefits all across the globe. " $\mathrm{m}$-health to Improve TB Care" is also now a new upcoming area with a potential for mobile health ( $\mathrm{m}$-health) to revolutionize the fight against $\mathrm{TB}^{[8]}$

\section{Current $\mathbf{m}$-health activities in developing countries: Indian initiatives}

Results of some of $\mathrm{m}$-health projects in developing countries such as India are very encouraging and they can continue to develop into long-term services, but many are not sustainable. The real power of $\mathrm{m}$-health in these projects is to enable the patient $\mathrm{s}$ and providers in these regions to help themselves. There are many externally and government-funded $\mathrm{m}$-health pilot-projects in the last decade in developing countries with ongoing $m$-health activity such as done in Indian set up, which are given below in Table 3..$^{[9,10]}$

\section{Role of $\mathbf{m}$-health and its possible incorporation in public health strategies of developing countries}

There are very limited studies in the literature, which have been carried out in the field, whatever there are primarily small pilot projects, which offer mixed results in terms of demonstrating the potential that fixed-line and mobile phones can support effective delivery of healthcare services. ${ }^{[11]}$ Kaplan suggests that functional and structural properties of mobile phones such as low start-up costs, text messaging and flexible payment plans, make them attractive to use as a health-care intervention. ${ }^{[1]}$ With the development of standardized health-related software applications, mobile phones can provide real-time feedback and
Table 1: Key themes and concepts emerged from the systematic review of literature

Authors contribution considered Key themes and concepts for systematic reviewing emerged from corresponding studies in literature

m-health web page access (2013)

Pew Internet and American Life

Project web page access (2012)

Kouadio et al.

Déglise et al.

m-health web page access (2013)

Interactive Research and

Development-paper (2012)

Istepanian et al.

Pew Internet and American Life

Project web page access (2012)

Sloninsky et al., Istepanian et al., Pew Internet and American

Life Project web page access

(2012), Kaplan, Lacal, Todrys and

Mechael and Mechael, Gurman

et al., Källander et al., Asangansi

and Braa, Crean, Curioso and

Mechael, Coelho

Sloninsky et al.

Kouadio et al.

Available $\mathrm{m}$-health working technologies for developing countries $^{[7,10]}$

M-health applications to public health using mobile devices ${ }^{[5-8]}$

Déglise et al.

Istepanian et al.

Nilsen et al.

Mechael et al.

$\mathrm{m}$-health $=$ Mobile health

Table 2: Currently available $m$-health technologies for use in developing countries ${ }^{[7]}$

Upcoming $\mathrm{m}$-health technologies

Patient monitoring devices

Mobile telemedicine/telecare devices

MP3 players for m-learning

Laptop computers

Microcomputers

Data collection software

Mobile operating system technology

m-health=Mobile-health

Table 3: Some $m$-health activities in India set up for replication in developing countries ${ }^{[9,10]}$

Type of $\mathrm{m}$-health

Role in public health system

application

Freedom HIVIAIDS

A mobile games application to promote HIVIAIDS awareness

Handhelds for health It uses mobile technologies (instead of pen and paper) to collect field data on disease or public health

SMS for requesting ambulance The ability to send a SMS to request an ambulance in a remote village

Clinicians and patients help- Services set up to enable clinicians lines and patients to do things more effectively

SMS = Short message service, AIDS = Acquired immunodeficiency syndrome, $\mathrm{HIV}=$ Human immunodeficiency virus, $\mathrm{m}$-health = Mobile health 
pre-programmed portable automated services that enable support to increasingly decentralized health systems as also advocated by Lacal and Mechael. ${ }^{[4,12,13]}$

\section{BCC}

In 2006, Kaplan noted the use of mobile phones for the "express purpose of supporting or altering one or more health outcomes" from BCC strategy given through mobile phones. He noted that, for direct interventions via mobile and fixed-line telephones can be used to address health conditions such as patient blood sugar level monitoring for diabetes, telephone counseling for patients with breast cancer, adherence to medication for patients with TB and treatment compliance for a variety of conditions, attendance at health facility appointments, depression outcomes, immunization rates, asthma management and smoking cessation and such kind of m-health activity can be useful for the public health system of developing countries. ${ }^{[4,11-13]}$

Resources have also now been allocated to developing m-health interventions, like use of mobile technology for BCC. Although the majority of mobile phone users world-wide live in the developing countries, most research evaluating BCC m-health interventions has taken place in developed countries. Although $\mathrm{m}$-health is viewed as a promising tool in developing countries with the ability to foster behavior change, more evaluations of current interventions are required to establish stronger evidence and corresponding evidence based practice. ${ }^{[14]}$

\section{Telemedicine}

In the area of telemedicine, the types of guidance that can be provided by $m$-health can vary depending on the capacity to assess a case with or without images, a physical examination, or laboratory tests and health conditions with complicated diagnostic measures might not benefit from remote consultations, requiring in-patient diagnosis and treatment as suggested by Mechael. ${ }^{[13]}$ Specialized protocols and training are also needed to identify the situations in which phone or internet based and other technology-enabled consultations are appropriate. Care must be taken to maximize their benefits by closely assessing the sorts of information to be gathered and communicated, which is advocated by Mechael. ${ }^{[13]}$

Mobile phones in low and middle income countries are often shared among household members as noted by Mechael. ${ }^{[13]}$ In a recent review of telemedicine policies in Africa, it was revealed that while most Ministries of Health have places to engage in telemedicine, they do not have policies associated with these practices. In order to protect patients' and providers' rights, national and international ethical and legal frameworks are needed to guide the appropriate use of telemedicine. Secure information within mobile communication environments is crucial to maintaining patients' rights to confidentiality as suggested by Todrys and Mechael. ${ }^{[15]}$ What is required is legal frameworks and liability boundaries, which are also very important to provide guidance on the appropriate use of tele-medical systems within national as well as across borders as suggested by Istepanian et al. and Lacal. ${ }^{[9,12]}$

Review of the telemedicine literature also revealed the following 5 studies: In a review study by Källander et al. it was suggested that there is promising evidence that $\mathrm{m}$-health can be used to deliver increased and enhanced health-care services to individuals and communities as well as helping to strengthen health systems through support for the performance of health-care workers by the dissemination of clinical updates, learning materials and reminders, particularly in underserved rural locations in low-and middle-income countries where community health workers can deliver integrated community case management to children sick with diarrhea, pneumonia and malaria. ${ }^{[16]}$

In an another study by Asangansi and Braa it was noted that major challenge for national health information systems in developing countries is their scalability and sustainability of m-health at the lowest levels where primary health-care is delivered through telemedicine approach, ${ }^{[17]}$ whereas Crean was of opinion that a comprehensive, long-term investment strategy for e-health and $\mathrm{m}$-health is needed and specialized financing techniques and sustained support from investors can accelerate the expansion of mature technologies to larger markets, accelerating global health impacts in tele-medicine approaches. ${ }^{[18]}$

In an another study by Curioso and Mechael, it was found that in both the global-north and global-south countries as well as developing countries in the global "South" are coming with m-health applications, which can enable health workers to collect and organize data, access diagnostic and treatment support and promote healthy behavior and their use is accelerating. ${ }^{[19]}$

Another important study by Coelho in 2011 proposed a framework, which can increase collaboration between the referring primary care physician and specialist, to prioritize institution of key services for telemedicine and highlighted the important process of e-referral, which uses electronic communication for making referrals to specialty care telemedicine. ${ }^{[20]}$

\section{m-health approaches in public and private health sectors of India for replication in developing countries}

$\mathrm{m}$-health and e-health are now entering into India's primary healthcare system as the health ministry have planned to go hi-tech, in this direction, the steering committee on $12^{\text {th }}$ Five Year Plan of India on health said that in the $12^{\text {th }}$ plan (2012-2017), all district hospitals would be linked to leading tertiary care centers through telemedicine; Skype and audio visual media and $\mathrm{m}$-health will be used to speed up transmission of data in this. Hence, the Government of India now has a major policy initiative in $\mathrm{m}$-health, which can also be replicated in other developing countries. Consequently, on lines of Indian government efforts, some private groups in India are also exploring areas of $\mathrm{m}$-health, which can also be tried in other developing countries. Such examples are as given below: 
1. Non-emergency help lines

2. Emergency help lines

3. Apollo - Aircel mobile health-care

4. Apollo M.I.N.D Line

5. Apollo telemedicine

6. Apollo Prism

7. Airtel Doctor

8. Apollo Munich, ICICI Lombard Health Insurance Companies

9. Med-India web site

\section{Key strengths and weaknesses of $\mathbf{m}$-health technology}

$\mathrm{m}$-health has grown rapidly in a very short period of time, but it requires a more thorough and scientific approach in its understanding and evaluating its progress. ${ }^{[21]}$ It requires a solid, interdisciplinary scientific approach for the rapid change associated with technological progress. ${ }^{[22]}$ $\mathrm{m}$-health can significantly change the way health-care of the future is practiced, but the human factors are more difficult to overcome, rather than the technological ones. The key barriers in $\mathrm{m}$-health are language, timing of messages, mobile network fluctuations, lack of financial incentives, data privacy and mobile phone turnover. ${ }^{[6]}$ Some common problems found in literature on $\mathrm{m}$-health are as given below:

a m-health products and services without proper consideration of patient privacy.

b. For sustainability of $\mathrm{m}$-health programs, key building blocks and strong partnerships should form the foundation. ${ }^{[5]}$

There are a number of other challenges and barriers that ought to be acknowledged within the discussion of expanding the benefits of $\mathrm{m}$-health in low and middle income countries, such as cost at the macro systems level ${ }^{[9,12]}$ as well as at the level of the individual citizen and healthcare provider. ${ }^{[13]} \mathrm{A}$ key aspect for any of these $\mathrm{m}$-health technology systems to work is that they should be affordable at any point of use. A billing structure must also be implemented that allows for a "reverse cost" approach, i.e., the Ministry of health or other responsible party will pay for it. ${ }^{[4]}$

\section{Pilot studies in $\mathbf{m}$-health area in Indian set up: Real-time-bio-surveillance-program (RTBP)}

The RTBP pilot, which was initiated to monitor the health status in India set up, found that the RTBP via m-health can reduce expenses, introduce benefits and improve the efficiencies in disease surveillance and mitigation in India and this approach was also found to be useful in Srilankan health system. ${ }^{[23]}$

\section{CONCLUSIONS}

Mobile technology can change the health-care delivery in the developing countries, by giving people who live in rural villages; the ability to connect with doctors, nurses and other health-care workers in major cities. $\mathrm{m}$-health has the potential to improve health outcomes in the long run in the developing countries as seen from Indian initiatives. The $\mathrm{m}$-health industry needs some regulatory strategies from government in order to focus on key priorities of health-care in developing countries, so that we can properly utilize the $\mathrm{m}$-health area for improvement of health of people in developing countries, otherwise most $m$-health projects will not reach their final incorporation stage in public health systems and will fall rapidly and moreover we will not be able to standardize m-health approaches. $\mathrm{m}$-health regulation will improve health outcomes in long run, so they are very important. Technological solutions for $\mathrm{m}$-health must be designed to meet local needs in practical and measurable ways to contribute to the MDGs via improvement of maternal and child health with the proper use of $\mathrm{m}$-health applications. There is also a critical need within $\mathrm{m}$-health area to evaluate the benefits and pitfalls of technology applications and their ability to promote the desired health outcomes. Further research in this field is required, which should focus on targeted exploratory and meta-analytic studies on the use of $\mathrm{m}$-health technology to improve the status of the public health in developing countries.

\section{REFERENCES}

1. Mishra UK. Amar Ujala News Paper India (Meerut ed). [Original Source: Research Firm Gartner], 2013. p. 10.

2. Cipresso P, Serino S, Villani D, Repetto C, Selitti L, Albani G, et al. Is your phone so smart to affect your states? An exploratory study based on psycho-physiological measures. Neurocomputing 2012;84:23-30.

3. Vital Wave Consulting. M-Health for Development: The Opportunity of Mobile Technology for Healthcare in the Developing World. United States: United Nations Foundation, Vodafone Foundation; 2009. p. 9.

4. Sloninsky D, Patricia Y, Mechael N. [WHO] Towards the Development of an m-Health Strategy: A Literature Review: WHO; 2008-7. p. 1-62.

5. Kouadio IK, Ghazi HF, Maimaiti N, Rahimi A, Aljunid SM. Potential of mobile technology in meeting the public health needs indevelopingcountries. BMC Public Health 2012;12 Suppl 2:A13.

6. Déglise C, Suggs LS, Odermatt P. SMS for disease control in developing countries: A systematic review of mobile health applications. J Telemed Telecrae 2012;18:273-81.

7. M-health (Other m-health technologies), c2013. Available from: http:// www.en.wikipedia.org/wiki/MHealth. [Last updated on 2013 Aug 15; Last cited on 2013 Aug 23].

8. M-health to Improve TB Care. Public Health Education and Awareness. [Interactive Research and Development paper], c2012. Available from: http://www.mobileactive.org/issue-categories/public-health-educationand-awareness. [Last updated on 2012 May 29; Last cited on 2013 Aug 23].

9. Istepanian R, Laxminarayan S, Pattichis CS, editors. M-Health: Emerging Mobile Health Systems. United States: Springer; 2005.

10. Pew Internet \& American Life Project, c2012. Available from: http:// www.pew-internet.org. [Last updated on 2012 Nov 10; Last cited on 2012 Nov 10].

11. Kaplan WA. Can the ubiquitous power of mobile phones be used to improve health outcomes in developing countries? Global Health 2006;2:9.

12. Lacal J. Cell phones and tele-medicine. In: Healthcom, editor. The Fifth International Workshop on Enterprise Networking and Computing in Healthcare Industry. Santa Monica, California; 2003.

13. Mechael P. Exploring Health-related Uses of Mobile Phones: An Egyptian Case Study, Public Health \& Policy. London: London School of Hygiene and Tropical Medicine; 2006. p. 264.

14. Gurman TA, Rubin SE, Roess AA. Effectiveness of mHealth behavior change communication interventions in developing countries: $A$ systematic review of the literature. J Health Commun 2012;17 Suppl $1: 82-104$

15. Todrys K, Mechael P. The Ethics of Telemedicine in Africa: The Millennium Villages Project Experience. Africa: The Earth Institute, Pending Publication; 2008. 
16. Källander K, Tibenderana JK, Akpogheneta OJ, Strachan DL, Hill Z, ten Asbroek $\mathrm{AH}$, et al. Mobile health (mHealth) approaches and lessons for increased performance and retention of community health workers in low- and middle-income countries: A review. J Med Internet Res 2013;15:e17.

17. Asangansi I, Braa K. The emergence of mobile-supported national health information systems in developing countries. Stud Health Technol Inform 2010;160:540-4.

18. Crean $\mathrm{KW}$. Accelerating innovation in information and communication technology for health. Health Aff (Millwood) 2010;29:278-83.

19. Curioso WH, Mechael PN. Enhancing 'M-health' with south-to-south collaborations. Health Aff (Millwood) 2010;29:264-7.

20. Coelho KR. Identifying telemedicine services to improve access to specialty care for the underserved in the San Francisco safety net. Int J Telemed Appl 2011;2011:523161.

21. Mechael P, Nemser B, Cosmaciuc R, Cole-Lewis H, Ohemeng-Dapaah S,
Dusabe S, et al. Capitalizing on the characteristics of mHealth to evaluate its impact. J Health Commun 2012;17 Suppl 1:62-6.

22. Nilsen W, Kumar S, Shar A, Varoquiers C, Wiley T, Riley WT, et al. Advancing the science of mHealth. J Health Commun 2012;17 Suppl 1:5-10.

23. Waidyanathan, Nuwan, Sampath, Chaminduand M, Ganesan. M-Health Revolutionizing Public Health: An Economic Study. $5^{\text {th }}$ Communication Policy Research South Conference (CPRsouth5), Xi'an, China, 2010 Dec 8, c2013. (SSRN). Available from: http://www.ssrn.com/abstract=1725165. [Last updated on 2010 Dec 08; last cited on 2013 Aug 23].

How to cite this article: Davey S, Davey A. Mobile-health technology: Can it Strengthen and improve public health systems of other developing countries as per Indian strategies? Asystematic review of the literature. Int J Med Public Health 2014;4:40-5.

Source of Support: Nil, Conflict of Interest: None declared. 